\title{
Public Health Spending and Health Outcomes in Kenya
}

\author{
James Murunga, MA \\ Evans Geoffrey Mogeni, MA \\ Dorothy Ngina Kimolo, $M A$ \\ Department of Economics, Machakos University, Kenya
}

\begin{abstract}
Health is important for sustainable economic performance of a country. This study seeks to investigate the effectiveness of public health spending on health outcomes. This is obtained by estimating a health production function for Kenya. In the study, infant mortality rate is used to measure health outcomes. The study uses time series data running from 1984 to 2015. The data is obtained from World Bank database and Kenya National Bureau of Statistics Economic Surveys. Error Correction Model (ECM) is adopted due to presence of cointegration. The results show that public expenditure on average influence health outcomes in Kenya. These results therefore provide evidence to support that increase in public expenditure improves health outcomes. The other factor that is found to be important determinant of health outcomes in Kenya is child immunization. The major policy implication of this study is that Kenyan government should increase budgetary allocation to health sector. In addition, government of Kenya should allocate more resources to child immunization.
\end{abstract}

Keywords: health outcomes, public health expenditure, Kenya.

\subsection{Introduction}

Human capital is a key determinant of economic growth at both macro and micro levels (Wilson and Briscoe, 2004, Becker, 1964). Precisely, the development of health capital results to economic growth through increase in healthy time for both market and non-market activities (Grossman, 1972; Muurinen, 1982). Recognition of the importance of human capital has therefore made several governments over the world resort to improvement of health capital. These thoughts culminated into an Abuja Declaration of 2001 where Sub-Saharan governments agreed to allocate 15 percent of their fiscal year budgets to their health sectors (Republic of Kenya, 2012). 
In less and medium income countries, health care is mainly financed by out of pocket expenditure (OOPE). Households that are not under any form of medical cover face the risk of spending large sums of money when they become sick. Such unforeseen medical expenditures sometimes may exhaust household's source of livelihood and sometimes even force it to borrow loans from banks and friends. These unforeseen medical expenditures may reduce household's standards of living (Krishna, 2006).

The need for public investment in health care has received a tremendous attention. According to proponents of this initiative, public investment in health reduces the size of out of pocket expenditure thus relieving the population from poverty occasioned by catastrophic health expenditure. Recently financial access in terms of health insurance has been established as a key instrument to offer financial protection and also achieve universal health care (WHO, 2010). Studies on less and medium developed countries reveal that OOPE are high and are pushing many families into poverty (Galarraga et al., 2010).

\subsection{Health Outcome and Disease Burden in Kenya}

Kenya's life expectancy is averaged at 61 years and this is an improvement as compared to the past few years. The major hindrance to improvement in life expectancy is death as a result of HIV/AIDS and a comparatively high under 5 child mortality. A larger proportion of the Kenyan population is made up of young people. In comparison to other African countries, Kenya is seen to be better in terms of life expectancy. The life expectancy of Uganda, Zambia, South Africa and Nigeria are 59 years, 58 years, 60 years and 55 years, respectively (The Dutch Republic, 2016).

The Kenyan government has made substantial efforts to improve health outcomes as well as use of the health services. These efforts have been captured through the decrease in child mortality and decreased burden of major communicable diseases as compared to ten years ago. Other notable improvement is reduction in under 5 child mortality rate by 54 percent between 2003 and 2014. The number of under 5 death rate was 115 in 1000 live birth in 2003 but reduced to 52 in 1000 live birth in 2014. Further, there was an improvement in infant mortality rate. The country's infant mortality rate decreased from 77 in 1000 live births in 2003 to 39 in 1000 live birth in 2014. However, neonatal mortality remains high contributing about 35 percent of the infant mortality rate. On maternal health, the maternal death rate has remained high at 362 deaths per 100,000 live births. This number is still high as compared to global statistics which shows a great decline world maternal death rate from 400 maternal deaths per 100,000 live births in 1990 to 210 maternal deaths per 100,000 live births in 2010 (Republic of Kenya, 2017). Another effort to realize improved health outcome in the country can be 
identified in the fight against HIV/AIDS. The need for improved health outcome has seen HIV prevalence rate among the adult population decrease from 11 percent in 1990s to 6 percent in 2015 (Republic of Kenya, 2015). Though the burden of non-communicable diseases has slightly reduced, they still account for many deaths in the country. Hospital data indicates that about 50 to 70 percent of all hospital admissions are associated with noncommunicable diseases. With regards to deaths, the data shows that about 50 percent of the total inpatient deaths are as a result of these diseases. Other major causes of deaths in Kenya include perinatal conditions, HIV/AIDS, diarrhoeal diseases and lower respiratory tract infections. The current total yearly death in Kenya is about 420,000 people. Out of these deaths, communicable diseases account for about 270,000 deaths while noncommunicable diseases account for about 110,000 deaths. Injuries account for about 40,000 deaths (Republic of Kenya, 2012).

\subsection{Health Financing in Kenya}

Health care in Kenya is financed from three sources namely government expenditure, out of pocket expenditure and donors (Munge \& Briggs, 2013). In 2017/18 fiscal year, the government of Kenya allocated a total of KES 61.6 billion to health sector. Out of this, pro-poor budget allocations were as follows: KES 900 for free primary healthcare, KES 300 million for health insurance for older people and people with disabilities, KES 4.3 for free maternal healthcare and KES 3.4 billion for special grant (Republic of Kenya, 2017).

Health care access in Kenya is yet to be made accessible to all Kenyans since the out of pocket payments needed are too high. For instance, in a survey carried out in the country it was revealed that 38 of the sick people showed that they could not access medical services since they do not have money to pay for the services. To show that many Kenyans do not access health care services due to high use fees, number of mothers and patients looking for health services increased as a result of doing away with user fees in health centres and dispensaries (Munge \& Briggs, 2013).

Donor funding is a very important component of health care financing in Kenya. It not only augments government's budgetary allocation but also support specific programmes for instance HIV/AIDS. For example, in 2009/10, donor funding contributed about 32 percent of total health spending but decreased to 22 percent in 2015/2016 (Ministry of Health, 2016). It is usually believed that a rise in donor funding leads to a decrease in out of pocket health expenditures as the major source of healthcare finance. 


\subsection{The Statement of the Problem}

Provision of quality health care is viewed as an important policy element to enhance broad-based economic performance. Diseases for instance HIV/AIDS, non-communicable are known to impede economic growth of many developing countries. Taking note of the importance of health in economic growth, every country allocates huge amount of public funds to the provision of health care with hope this would improve health of her population which can positively contribute to the country's economic performance. Though increased expenditure on social services by governments of developing countries like Kenya is viewed as a good gesture, enhancement of service delivery may not be guaranteed. Poor budget administration has been recognized as one of the major reasons for failure of public spending in developing countries (Yaqup et al., 2012). In Kenya, for instance, the government has increased budgetary allocation on health provision but health status of Kenyans has not improved significantly. For instance, Kenya's universal health coverage (UHC) service coverage index is 46 which is much less than 86 recorded countries that are doing well in terms of UHC coverage (World Health Organization, 2017). It therefore becomes imperative to examine the impact of public health spending on health outcomes in Kenya. This study therefore examines the effect of public health spending on health outcomes in Kenya.

The subject of public spending and health outcomes has attracted attention of quite a number of scholars. Among the studies that have investigated this subject include Kyalo (2013); Bidzha (2015), Brown et al. (2014), Hu \& Mendoza (2013), Craigwell et al. (2012), Yaqup et al. (2012), Akinkugbe and Mohanoe (2009), Filmer \& Pritchet (1999), and more recently, Novignon \& Lawanson (2017). However, most of these earlier studies are not focused on Kenya. The study on Kenya did not exhaust controlling for determinants of health outcomes. For instance, the study neglected female literacy which is an important determinant of child mortality.

\subsection{Research Questions}

The questions which the study seeks to answer are as follows:

i. How does public health spending affect health outcomes in Kenya?

ii. How does public health spending affect infant mortality rate in Kenya?

iii. What policy recommendation can be derived from the study findings?

\subsection{Objectives of the Study}

The overall objective of the study is to investigate the effect of public health spending on health outcomes in Kenya. Achievement of overall objective is guided by the following specific objectives. 
i. To estimate the effect of public health expenditure on infant mortality rate in Kenya.

ii. To draw policy implications based on study findings.

\subsection{Significance of the Study}

The contribution of this study is to provide insightful information to workers in the health sector of the national and county governments regarding health financing. The study results may also be a point of reference for policy makers for them to formulate health policies targeting expenditure on health care. This study will enrich literature on health sector financing and health outcomes. This is because the study will be an addition to already existing literature in this area of health economics. The study findings may also be of great importance to future researchers in the subject of health economics.

\subsection{Literature Review}

Bidzha (2015) investigated public health spending and health outcomes in South Africa using a panel data of 9 provinces. In the study, life expectancy and infant mortality rate were considered as measures of health outcomes. The study's findings showed that public health spending is important in reducing infant mortality and improving life expectancy. In another study, Brown et al. (2014) investigated public health expenditure and mortality among California county departments using Koyck distributed lag model. The study findings revealed that public health expenditure significantly reduces mortality. Hu \& Mendoza (2013) studied public health expenditure, quality of governance and child mortality rates using a panel data of 136 developing countries. Their findings reveal that public health expenditure and quality governance are important in reducing child mortality. Craigwell et al. (2012) also studied public expenditure, health care and health status among 19 Caribbean countries for the period spanning from 1995 to 2007 using pooled OLS model. The study results revealed that public health spending is statistically important in determining health status among the 19 Caribbean countries. Yaqup et al. (2012) studied the effectiveness of public health expenditure and governance. The study used time series data running from 1980 to 2008. The study used both OLS and Two Stage Least Square (2SLS) estimation techniques. Governance was measured by corruption perception index. The study findings revealed that infant mortality rate and under 5 response to increase in public health expenditure is negative when governance is considered in the model. Akinkugbe and Mohanoe (2009) studied public health expenditure and health status in Lesotho using error correction (ECM) model. This study's results reveal that apart from public health expenditure, availability of physician, female literacy level and child immunization positively determine health outcomes in Lesotho. Filmer \& Pritchet (1999) 
studied public health expenditure and health outcomes among 98 developing and developed countries using a cross- national of 1990. The study adopted under 5 and infant mortality as measures of health outcomes. This study's findings reveal that public health spending positively influences health outcomes among the 98 countries.

\subsection{Methodology}

\subsection{Theoretical Framework}

The study considered Grossman (1972) model to examine the impact of public health expenditure on health outcomes. This theoretical model envisages that individual health status is a function individual inputs and is specified as shown in equation 3.1 . $\mathrm{Y}=\mathrm{f}(\mathrm{W})$

Where $\mathrm{Y}$ measures individual health status and $\mathrm{W}$ represents individual inputs to the health function. With such health production function, one can easily carry out and empirically estimate the effect of health expenditure on health status. In the empirical estimation, health expenditure is used as a proxy for healthcare. Aggregate health production function is considered because it allows the estimation of overall effect of the utilization of healthcare on the health status of the population.

\subsection{Empirical Model}

From the above theoretical model, the study considered infant mortality rate as the measure of health outcome. Apart from public health expenditure, female literacy, number of doctors, child immunization and number of doctors are also included as explanatory variables. The estimated model is as specified in equation 3.2

lninfmort $_{t}=\beta_{0}+\beta_{1}$ lnphexp $_{t}+\beta_{2}$ lnflitrate $_{t}+\beta_{3}$ lndocs $_{t}+$ $\beta_{4}$ lnimune $_{t}+\beta_{5}$ lnpercapgdp $_{t}+$

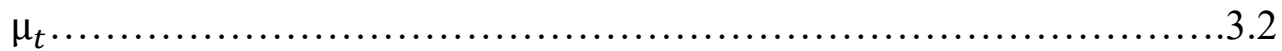

Where lninfmort is natural logarithm of infant mortality rate, lnphexp is natural logarithm of public health expenditure, Inflitrate is natural logarithm of female literacy rate, lndocs is natural logarithm of the number of doctors ,lnimune is natural logarithm of child immunization, percapgdp is natural logarithm of per capita GDP while $\beta_{0}, \beta_{1}, \beta_{2}, \beta_{3}$, $\beta_{4}$ and $\beta_{5}$ are parameters. $\mu$ is the error term and tis time trend.

\subsection{Variable Definition and Data Source}

In the empirical analysis, data from 1984 to 2015 was used. The data used in the study was obtained from World Bank data base, Kenya National Bureau of Statistics (KNBS) publications and UNICEF database. Infant mortality is measured by the number of deaths of infants under one year old 
per 1,000 live births. Public health expenditure is measured by amount in Kenya shillings allocated to health sector by the government of Kenya. Literacy rate among the female adults is measured by the proportion of female of 15 years and above with ability to read, write and be able to understand short and simple statements concerning their everyday life. Immunization is measured by proportion of children between the age of 12 months and 23 months who are vaccinated before attaining 12 months. Further, doctors are measured as the number of doctors per 100000 population. Lastly, per capita GDP is measured as the total monetary value of every individual in the country. It is given in Kenya shillings.

\subsection{Empirical Results and Data Analysis}

\subsection{Descriptive Statistics}

Descriptive statistics deals with measures of central location and measures of spread. Table 4.1 shows the descriptive statistics of infant mortality rate, public health expenditure, female literacy rate, number of doctors per 100000 population, child immunization and per capita GDP.

Table 4.1: Descriptive Statistics

\begin{tabular}{|c|c|c|c|c|c|}
\hline Variables & Observations & Mean & $\begin{array}{c}\text { Standard } \\
\text { Deviation }\end{array}$ & $\begin{array}{c}\text { Minimum } \\
\text { value }\end{array}$ & $\begin{array}{c}\text { Maximum } \\
\text { value }\end{array}$ \\
\hline $\begin{array}{c}\text { Infant mortality } \\
\text { rate }\end{array}$ & 32 & 4.13 & 0.19 & 3.78 & 4.33 \\
\hline $\begin{array}{c}\text { Public health } \\
\text { expenditure }\end{array}$ & 32 & 23.13 & 1.15 & 21.26 & 25.05 \\
\hline $\begin{array}{c}\text { Female literacy } \\
\text { rate }\end{array}$ & 32 & 4.62 & 0.08 & 4.49 & 4.76 \\
\hline $\begin{array}{c}\text { Number of } \\
\text { Doctors }\end{array}$ & 32 & 2.77 & 0.14 & 2.58 & 3.09 \\
\hline $\begin{array}{c}\text { Child } \\
\text { Immunization }\end{array}$ & 32 & 4.31 & 0.17 & 3.83 & 4.54 \\
\hline Per capita GDP & 32 & 10.17 & 1.03 & 8.46 & 11.81 \\
\hline
\end{tabular}

Source: Author's Computation based on data from various sources

Table 4.1 shows that a total of 32 observations were considered in the study. Standard deviation shows how the values are spread from their mean and is useful for comparison purposes. For example, the data shows that natural logarithm of public health expenditure has a larger spread in comparison to other variables in the study. The natural logarithm of infant mortality rate has a spread of 0.19 from its mean of 4.13. The table also illustrates minimum and maximum value for each variable. For example, the minimum value of the natural logarithm of public health expenditure is 21.26 while the maximum value is 25.05 . 


\subsection{Diagnostic Tests}

\subsubsection{Serial correlation}

To test whether there was correlation among the error terms, Breusch Godfrey test was adopted. The test results are as shown in Table 4.2.

\section{Table 4.2: Serial correlation}

\begin{tabular}{|c|c|c|c|}
\hline \multicolumn{5}{|c|}{ Breusch-Godfrey LM test for autocorrelation } \\
H0: no serial correlation \\
\hline Chiss(p) & Chi2 & Degrees of freedom & Prob>chi2 \\
\hline 1 & 0.135 & 1 & 0.7131 \\
\hline
\end{tabular}

Source: Author's Computation based on data from various sources

From Table 4.2 it was evident that serial correlation was absent since the p-value was insignificant leading to the acceptance of the above null hypothesis.

\subsubsection{Multicollinearity}

To test for relationship among the variables on the right hand side of the equation, the study adopted a Variance Inflation Factors (VIF) test. Presence of multicollinearity is revealed by a VIF index of greater than 10 (Nachtscheim, 2004). VIF is calculated from the coefficient of determination as shown below.

$$
V I F=\frac{1}{1-R^{2}}
$$

Where; $\mathrm{R}^{2}$ is the coefficient of determination. The VIF indices are shown in Table 4.3.

Table 4.3: VIF Test for Multicollinearity

\begin{tabular}{|c|c|c|}
\hline Variable & VIF & 1/VIF \\
\hline Per capita GDP & 12.26 & 0.081566 \\
\hline Public health expenditure & 8.17 & 0.122360 \\
\hline Number of Doctors & 5.12 & 0.195155 \\
\hline Child Immunization & 1.71 & 0.584134 \\
\hline Mean VIF & 5.70 & \\
\hline
\end{tabular}

Source: Author's Computation based on data from various sources

Multicollinearity test showed that public health expenditure, female literacy rate, number of doctors and child immunization had a VIF of less than 10 implying absence of multicollinearity. However, per capita GDP was found to have a VIF index greater than 10 signifying existence of multicollinearity. The study ignored this multicollinearity since the affected variable was a control variable in the study. 


\subsection{Stationary Test}

Stationarity is an important characteristic of time series. Stationary data means spurious regression problem and inconsistent estimate problem is avoided. Non-stationary series means there is at least a unit root. Augmented Dickey Fuller (ADF) test was applied on each variable to test for presence of a unit root. The results are illustrated in Table 4.4.

Table 4.4: Illustration of Stationarity in Levels

\begin{tabular}{|c|c|c|c|c|}
\hline Variable & Test statistic & $1 \%$ critical level & $5 \%$ critical level & $\begin{array}{c}10 \% \text { critical } \\
\text { level }\end{array}$ \\
\hline Public health expenditure & -1.704 & -3.709 & -2.983 & -2.623 \\
\hline Female literacy rate & -1.135 & -3.709 & -2.983 & -2.623 \\
\hline Number of doctors & -0.637 & -3.709 & -2.983 & -2.623 \\
\hline Child Immunization & -2.443 & -3.709 & -2.983 & -2.623 \\
\hline Per capita GDP & -0.453 & -3.709 & -2.983 & -2.623 \\
\hline
\end{tabular}

Source: Author's Computation based on data from various sources

From Table 4.4, it was evident that all the variables had at least a unit root at levels. The variables were differenced once. The results for stationarity status after first difference are shown in Table 4.5.

Table 4.5: Illustration of Stationarity (First Difference)

\begin{tabular}{|c|c|c|c|c|}
\hline Variable & $\begin{array}{c}\text { Test } \\
\text { statistic }\end{array}$ & $1 \%$ critical level & $5 \%$ critical level & $10 \%$ critical level \\
\hline D1infant mortality & -1.107 & -3.716 & -2.986 & -2.624 \\
\hline $\begin{array}{c}\text { D1public health } \\
\text { expenditure }\end{array}$ & -8.314 & -3.716 & -2.986 & -2.624 \\
\hline D1female literacy rate & -7.249 & -3.716 & -2.986 & -2.624 \\
\hline D1number of doctors & -7.550 & -3.716 & -2.986 & -2.624 \\
\hline D1childimmunization & -5.347 & -3.716 & -2.986 & -2.624 \\
\hline D1per capita GDP & -4.209 & -3.716 & -2.986 & -2.624 \\
\hline
\end{tabular}

Source: Author's Computation based on data from various sources

Results from first differencing showed that all variables except infant mortality rate had one unit root since they became stationary after differencing once. Infant mortality rate was subjected to second differencing. The results are shown in Table 4.6.

Table 4.6: Illustration of Stationarity (Second Difference)

\begin{tabular}{|c|c|c|c|c|}
\hline Variable & Test statistic & $1 \%$ critical level & $5 \%$ critical level & $10 \%$ critical level \\
\hline D2infant mortality & -5.946 & -3.723 & -2.989 & -2.625 \\
\hline
\end{tabular}

Source: Author's Computation based on data from various sources

From the results shown in Table 4.6, it was revealed that infant mortality rate is integrated of order 2 since the variables became stationary after differencing twice.

Since all the variables are non-stationary at levels, this required the study to test for presence of cointegration. To test this, the study adopted 
Johansen Cointegration test. Before carrying out Johansen cointegration test, the study had to establish number of lags to consider in the study. The study adopted both Vector Error Correction (VEC) and Vector Autoregressive (VAR) Lag Selection Criteria and the obtained results are shown in Table 4.7 Table 4.7: Lag length Selection Criteria

\begin{tabular}{|l|l|l|l|l|l|l|l|l|}
\hline \multicolumn{9}{|l|}{$\begin{array}{l}\text { Selection-order criteria } \\
\text { Sample: } 1984-2015\end{array}$} \\
\hline $\begin{array}{l}\text { Max } \\
\text { rank }\end{array}$ & LL & LR & Df & Prob & FPE & AIC & HQIC & SBIC \\
\hline 0 & 64.24 & & & & 0.000789 & -4.31409 & -4.22847 & -4.02613 \\
\hline 1 & 87.94 & 47.39 & 1 & 0.000 & 0.000148 & -5.99509 & -5.89519 & -5.65913 \\
\hline 2 & 88.33 & 0.7942 & 1 & 0.373 & 0.000155 & -5.95043 & -5.83626 & -5.56648 \\
\hline 3 & 88.36 & 0.0606 & 1 & 0.806 & 0.000168 & -5.8786 & -5.75016 & -5.44665 \\
\hline 4 & 98.88 & $21.036^{*}$ & 1 & 0.000 & $\begin{array}{l}0.000084 \\
*\end{array}$ & $-6.58363^{*}$ & $-6.44092^{*}$ & $-6.10369^{*}$ \\
\hline
\end{tabular}

Source: Author's Computation based on data from various sources

From the Table 4.7, FPE criteria showed that the study should consider 4 lags. The rule of thumb for AIC, HQIC and SBIC is that maximum rank with least magnitude should be considered. These three criteria suggested that the study should consider 4 lags as suggested by all the criteria. Having identified lag length, the study proceeded to testing for presence of long run relationship using Johansen cointegration test and the results are shown in Table 4.8.

Table 4.8: Johansen Test for Cointegration (Max Statistic Model)

\begin{tabular}{|c|c|c|c|c|c|c|}
\hline \multirow{2}{*}{\multicolumn{4}{|c|}{$\begin{array}{l}\text { Trend: None } \\
\text { Sample: } 1984-2015\end{array}$}} & \multicolumn{3}{|c|}{ Number of observation $=27$} \\
\hline & & & & Numbe & lags & $=4$ lags \\
\hline $\begin{array}{l}\text { Maximum } \\
\text { rank }\end{array}$ & parms & LL & Eigenvalue & Max statistic & $\begin{array}{l}5 \% \\
\text { Value }\end{array}$ & critical \\
\hline 0 & 108 & . & . & $\cdot$ & 36.36 & \\
\hline 1 & 119 & . & 1.00000 & & 30.04 & \\
\hline 2 & 128 & . & 1.00000 & 920.64 & 23.80 & \\
\hline 3 & 135 & . & 1.00000 & 47.89 & 17.89 & \\
\hline 4 & 140 & . & 0.83033 & 11.82 & 11.44 & \\
\hline 5 & 143 & . & 0.35464 & 1.98 & 3.84 & \\
\hline 6 & 144 & . & 0.07077 & & & \\
\hline
\end{tabular}

Source: Author's Computation based on data from various sources

Max statistic results in Table 4.7 revealed that at maximum rank 5, the max statistic was less than the critical value at 5 percent significance level which implied that null hypothesis of 5 cointegrating equations was not be accepted. The Johansen cointegration test therefore revealed presence of cointegration suggesting an adoption of Error Correction Model (ECM) framework (Table 4.8).

The statistics revealed a negative and significant Error Correction Term (ECT) revealing of long run causality that runs from infant mortality rate to public health expenditure, female literacy rate, number of doctors per 
100000 population, immunization and per capita GDP. In addition, coefficients of lag one, two and three of the public expenditure are statistically significant at 5 percent significant level.

The signs of the three variables indicate that an increase in public health spending results to a decrease in infant mortality rate in Kenya. In addition, the coefficient of lag one of child immunization was found to be significant at 5 percent level of significant. The sign of the coefficient of child immunization implies that improvement in child immunization results to a decline in infant mortality rate in Kenya. Further, the coefficient of lag one of the number of doctors per 100000 population was found to be significant. The sign of this coefficient showed that an increase in number of doctors per 100000 population results to increase in infant mortality rate.

Table 4.8: Regression Results for Error Correction Model

\begin{tabular}{|c|c|c|c|c|}
\hline \multicolumn{2}{|c|}{$\begin{array}{c}\text { Dependent Variable : Infant Mortality } \\
\text { Sample }\end{array}$} & \multicolumn{3}{|c|}{$\begin{array}{l}\text { Method : Error-correction model } \\
984-2015\end{array}$} \\
\hline & Coefficient & Standard Error & $\mathrm{T}$ & $\mathrm{P}>\mathrm{Z}$ \\
\hline \multicolumn{5}{|l|}{ D_ infant mortality rate } \\
\hline L1.(Error Correction term) & -0.647 & 0.356 & -1.82 & $0.069 * * *$ \\
\hline L1 infant mortality rate & 0.488 & 0.309 & 1.58 & 0.114 \\
\hline L2 infant mortality rate & 0.1694 & 0.139 & 1.22 & 0.222 \\
\hline L3 infant mortality rate & 0.309 & 0.195 & 1.59 & 0.112 \\
\hline L1 public health expenditure & -0.0421 & 0.017 & -2.53 & $0.011 * *$ \\
\hline L2 public heath expenditure & -0.0325 & 0.014 & -2.40 & $0.016^{* *}$ \\
\hline L3 public health expenditure & -0.023 & 0.009 & -2.43 & $0.015 * *$ \\
\hline L1female literacy rate & 0.717 & 0.496 & 1.45 & 0.148 \\
\hline L2 female literacy rate & 0.403 & 0.277 & 1.46 & 0.145 \\
\hline L3 female literacy rate & 0.161 & 0.142 & 1.13 & 0.257 \\
\hline L1 number of doctors & 0.186 & 0.083 & 2.24 & $0.025 * *$ \\
\hline L2 number of doctors. & 0.192 & 0.122 & 1.57 & 0.116 \\
\hline L3 number of doctors & 0.044 & 0.0576 & 0.76 & 0.446 \\
\hline L1 child immunization & -0.048 & 0.026 & -1.85 & $0.064 * *$ \\
\hline L2 child immunization & -0.017 & 0.0257 & -0.64 & 0.520 \\
\hline L3 child immunization & 0.0066 & 0.020 & 0.32 & 0.748 \\
\hline L1 per capita GDP & 0.200 & 0.127 & 1.58 & 0.115 \\
\hline L2 per capita GDP & 0.106 & 0.099 & 1.07 & 0.284 \\
\hline L3 per capita GDP & 0.040 & 0.031 & 1.30 & 0.195 \\
\hline Constant & -0.003 & 0.000881 & -2.85 & $0.004 * *$ \\
\hline \multicolumn{5}{|c|}{ R-squared $=0.9926 ; \quad \mathrm{P}>$ chi $2 \quad=0.0000^{*}$} \\
\hline
\end{tabular}

Source: Author's Computation based on data from various sources

\subsection{Conclusion and Policy Recommendation}

\subsection{Conclusion}

The allocation to the health sector in Kenya has continued to increase for the last decade though is still below the Abuja declaration of 2001 which called for governments to increase funding and allocate $15 \%$ of the national 
budget to health. The country has also made strides in improvement of health outcomes. For instance, the country has witnessed reduction in infant and under 5 mortalities. The major challenge is neonatal mortality which has remained high and contributes about 35 percent of the infant mortality rate. On maternal health, the maternal death rate has remained high at 362 deaths per 100000 live births.

This paper sought to investigate public health spending on health outcomes in Kenya. To achieve the objective, the study adopted Grossman (1972) model to estimate the relationship between public health spending and health outcomes in Kenya. The study used infant mortality rate as the measure of health outcome. The study considered female literacy rate, number of doctors per 100000 population, child immunization and per capita GDP as control variables. The study findings revealed that public health financing and child immunization to be important determinants of infant mortality rate in Kenya.

\subsection{Policy Recommendation}

Based on the study findings of this study, the key recommendation is for the Kenyan government to increase budgetary allocation to public health in order to realize an improvement in the country's health outcomes. In addition, the government should increase resources towards child immunization. The analysis suggests that these measures can result to improved health outcomes in Kenya.

\section{References:}

1. Akinkugbe, O., \& Mohanoe, M. (2009). Public health expenditure as a determinant of health status in Lesotho. Social Work in Public Health, 24(1-2): 131-147.

2. Becker, G. (1964). human capital, NY. GS Becker.

3. Bidzha, M. L. (2015). The effectiveness of public health spending in South Africa. Unpublished Master degree project, University of Johannesburg, South Africa.

4. Brown, T. T., Martinez-Gutierrez, M. S., \& Navab, B. (2014). The impact of changes in county public health expenditures on general health in the population. Health Economics, Policy and Law, 9(3): 251-269.

5. Craigwell, R., Bynoe, D., \& Lowe, S. (2012). The effectiveness of government expenditure on education and health care in the Caribbean. International Journal of Development Issues, 11(1): 4-18.

6. Filmer, D., \& Pritchett, L. 1999. The impact of public spending on health: does money matter? Social Science \& Medicine 49(10): 13091323. 
7. Galarraga, O., Sosa-Rubi, S.G., Salina-Rodrigues, A. and SesmaVasquez, S. (2010). Health insurance for the poor: impact on catastrophic and out-of-pocket health expenditures in Mexico. Eur J Health Econ, 11: 437-47.

8. Grossman, M. (1972). On the concept of health capital and the demand for health. The Journal of Political Economy, 80(2): 223-255.

9. Hu, B., \& Mendoza, R. U. (2013). Public health spending, governance and child health outcomes: revisiting the links. Journal of Human Development and Capabilities, 14(2): 285-311.

10. Krishna A. (2006). Pathways out of and into poverty in 36 villages of Andhra Pradesh. India World Dev, 34(2): 271-88.

11. Kyalo, K. M. (2013). Public Health Expenditure and Health Outcomes in Kenya. Unpublished MA Project, Kenyatta University, Kenya.

12. Ministry of Health, (2015). Kenya National Health Accounts 2012/13. Nairobi: Ministry of Health.

13. Ministry of Health, (2016). Kenya National Health Accounts 2015/16. Nairobi: Ministry of Health.

14. Munge, K., \& Briggs, A. H. (2013). The progressivity of health-care financing in Kenya. Health policy and planning, 29(7): 912-920.

15. Muurinen, J. M. (1982). Demand for health: a generalised Grossman model. Journal of Health Economics, 1(1):5-28.

16. Nachtscheim, C.J. Neter, J. (2004). Applied Linear Regression Models, 4th edition. Boston: McGraw-Hill Irwin.

17. Novignon, J., \& Lawanson, A. O. (2017). Health expenditure and child health outcomes in Sub-Saharan Africa. African Review of Economics and Finance, 9(1), 96-121.

18. Republic of Kenya, (2007). National Health Accounts (NHA) 2005/06. Ministry of Health

19. Republic of Kenya, (2014). Ministry of Health Ministerial Strategic and investment Plan, July 2014- June 2018. Nairobi: Government printer.

20. Republic of Kenya, (2017). Budget Speech for financial year 2017/18. Nairobi: Government printer.

21. Republic of Kenya, (2017). Economic Survey, Nairobi: Government printer.

22. Republic of Kenya. (2012). Ministry of Health. Kenya Health Policy 2012 - 2030. Nairobi: Government Printer.

23. Republic of Kenya. (2015). Kenya HIV AIDS Estimates. Nairobi: Government Printer.

24. Republic of Kenya. (2017). Kenya National Health Accounts 2015/2016. Nairobi: Government Printer. 
25. The Dutch Republic, (2016). Kenyan Healthcare Sector. Market Study Report: Opportunities for the Dutch Life Sciences \& Health sector.

26. Wilson, R. A., \& Briscoe, G. (2004). The impact of human capital on economic growth: a review. Impact of education and training. Third report on vocational training research in Europe: background report. Luxembourg: EUR-OP.

27. World Health Organization (2015). Kenya's Statistical Profile. Geneva: WHO publications

28. World Health Organization. (2010). The World Health Report 2010Health systems financing: the path to universal coverage. Geneva: World Health Organization.

29. World Health Organization. (2017). The World Health Report 2017Tracking Universal Health Coverage. Geneva: World Health Organization.

30. Yaqub, J. O., Ojapinwa, T. V., \& Yussuff, R. O. (2012). Public health expenditure and health outcome in Nigeria: the impact of governance. European Scientific Journal, ESJ, 8(13). 